\title{
Corrigendum: ASIP and TYR pigmentation variants associate with cutaneous melanoma and basal cell carcinoma
}

Daniel F Gudbjartsson, Patrick Sulem, Simon N Stacey, Alisa M Goldstein, Thorunn Rafnar, Bardur Sigurgeirsson,

Kristrun R Benediktsdottir, Kristin Thorisdottir, Rafn Ragnarsson, Steinunn G Sveinsdottir, Veronica Magnusson, Annika Lindblom, Konstantinos Kostulas, Rafael Botella-Estrada, Virtudes Soriano, Pablo Juberías, Matilde Grasa, Berta Saez, Raquel Andres,

Dominique Scherer, Peter Rudnai, Eugene Gurzau, Kvetoslava Koppova, Lambertus A Kiemeney, Margret Jakobsdottir, Stacy Steinberg, Agnar Helgason, Solveig Gretarsdottir, Margaret A Tucker, José I Mayordomo, Eduardo Nagore, Rajiv Kumar, Johan Hansson, Jon H Olafsson, Jeffrey Gulcher, Augustine Kong, Unnur Thorsteinsdottir \& Kari Stefansson

Nat. Genet. 40, 886-891 (2008); published online 18 May 2008; corrected after print 29 July 2008

In the version of this article initially published, there were two errors in the numbers reported in the abstract. The correct odds ratio for the association of the ASIP haplotype with risk of basal cell carcinoma is 1.35 , and the correct $P$ value for the association of the TYRP1 variant with risk of cutaneous melanoma is $4.3 \times 10^{-4}$. These errors have been corrected in the HTML and PDF versions of the article. 